To the Editors:

\title{
Iatrogenic Horner's syndrome: a rare complication of thyroid surgery
}

Horner's syndrome occurs due to damage to the ipsilateral cervical sympathetic chain. It is a rare complication of thyroidectomy. A 35-year old female underwent left hemithyroidectomy for a solitary thyroid nodule. She was euthyroid and had no history of previous neck surgery. The patient went home on the second postoperative day after uneventful recovery. One week later, the patient complained of inability to fully retract her left upper eyelid. On examination, she had left sided partial ptosis and meiosis. She had no features suggestive of impaired sweating or flushing on that side of the face. After 3 months, her symptoms had reduced, but she still had noticeable partial ptosis and meiosis. Histology of the removed specimen indicated a degenerating colloid nodule.

Horner's syndrome, originally described in 1869 [1], classically includes meiosis, partial ptosis, enophthalmos and anhidrosis. It follows the disruption of the fibres of the cervical sympathetic chain, which supply the radial muscle of the iris, the superior tarsal muscle (muscle of Mueller) and the sweat glands of the face.

Causes of Horner's syndrome include direct trauma to the neck, ischaemia of the brain stem, dissection of the carotid artery, thyroid and lung malignancy and iatrogenic causes. Among the last, Horner's syndrome has been noted following epidural analgesia, central venous cannulation, coronary artery bypass grafting, carotid endarterectomy, chest tube thoracostomy and tonsillectomy.
Horner's syndrome after thyroidectomy, is a rare complication, noted in less than $0.2-0.3 \%$ of cases [2]. In most cases the syndrome is incomplete, usually with the absence of vasomotor symptoms, as in our case. In one study $70 \%$ of cases reported permanent symptoms or incomplete recovery, although the follow up period was only 15 months [3].

The pathophysiology of Horner's syndrome following thyroidectomy remains unexplained. Theories include postoperative haematoma compressing the cervical sympathetic chain, ischaemia induced neural damage, stretching of the chain during retraction and direct damage especially in patients with anatomical variations $[3,4]$.

\section{References}

1. Horner JF. Über eine form von ptosis. Klinische Monatsblätter für Augenheilkunde, Stuttgart 1869; 7: 193-8.

2. Harding JL, Sywak MS, Sidhu S, Delbridge LW. Horner's syndrome in association with thyroid and parathyroid disease. ANZ Journal of Surgery 2004; 74: 442-5.

3. Cozzaglio L, Coladonato M, Doci R, et al. Horner's Syndrome as a complication of thyroidectomy: report of a case. Surgery Today 2008; 38: 1114-6.

4. Solomon P, Irish J, Gullane P. Horner's syndrome following a thyroidectomy. Journal of Otolaryngology 1993; 22: 454-6.

\section{W D D de Silva ${ }^{1}$, M S M de Soysa ${ }^{1}$, B L Perera ${ }^{1}$}

${ }^{1}$ Department of Surgery, District General Hospital, Gampaha, Sri Lanka.

Correspondence: WDDdeS, e-mail <desilva.dulantha@gmail.com>. Received 6 May and revised version accepted 30 May 2010. Competing interests: none declared. 